\title{
Short Term Modeling of the Nigerian Naira/United States Dollar Exchange Rate Using ARIMA Model
}

\author{
Guobadia Emwinloghosa Kenneth ${ }^{1}{ }^{2 *}$, Ibeakuzi Precious Onyedikachi ${ }^{3}$, Uadiale Kenneth Kevin ${ }^{4}$
}

${ }^{1}$ Department of Administration, Federal Medical Centre, Asaba, Delta State, Nigeria

${ }^{2}$ Department of Statistics, University of Benin, Benin, Nigeria

${ }^{3}$ Department of Statistics, Nnamdi Azikiwe University Awka, Nigeria

${ }^{4}$ Department of Mathematics and Statistics, Federal University Wukari, Taraba State, Nigeria

*Corresponding author: Guobadia Emwinloghosa Kenneth

Abstract

This paper attempts to model the exchange rate between Naira and U.S Dollar using Autoregressive Moving Average Models (ARIMA). From the examined models, ARIMA $(1,0,1)$ out-performed other models based on the lowest AIC, BIC and HQC values. The forecasted result suggests that Naira to Dollar exchange rate would slightly be on the increase in upcoming weeks.

Keywords: Exchange rate, ARIMA model, U.S.D, Naira, Augmented dickey-fuller test.

Copyright $\odot 2021$ The Author(s): This is an open-access article distributed under the terms of the Creative Commons Attribution 4.0 International License (CC BY-NC 4.0) which permits unrestricted use, distribution, and reproduction in any medium for non-commercial use provided the original author and source are credited.

\section{INTRODUCTION}

In finance, the rate at which one currency can be exchanged for another is the exchange rate between two currencies. It is often understood in terms of another currency as the value of one country's currency [1]. For example, an interbank exchange rate of 390 naira to the United States dollar means that 390 naira will be exchanged for each U.S $\$ 1$, in this case it is said that the price of a dollar in terms of naira is N390, or equivalent that the price of a naira in terms of dollars is $\$ 1 / 390$. A market-based exchange rate will change whenever the values of either of the two component currencies change. A currency will tend to become more valuable whenever demand for it is greater than the available supply. When demand is smaller than the supply available, it will become less valuable (this does not mean people no longer want money, kit just means they prefer holding their wealth in some other form, possibly another currency) [2]. The exchange rate is a relative price that, in terms of another currency, determines the value of a domestic currency. The currency is of vital importance for any potential investment in forecasting the foreign exchange rate, or at least predicting the trend correctly. One of the challenging applications of modern time series forecasting is exchange rate prediction. Inherently noisy, non-stationary and deterministically unstable are the prices Box et al., [3]. These features mean that there is no complete knowledge that could be extracted from the past actions of such markets in order to completely capture the dependency between future prices and past rates. Therefore, as it is believed that historical data is the main player in the process of prediction; historical data contains all these behaviors. The exchange rate fluctuates and requires a mathematical model that can reflect the fluctuations in an estimated way. With a class of structural time series models, exchange rate fluctuations can be studied in order to gain a better understanding of the underlying mechanism and to obtain more efficient estimates [4]. A suitable autoregressive model for the study of the Nigerian exchange rate for Naira against dollars is the main objective for this reason. The study is expected to be used in the performance of its mission by the government and policy makers in Nigeria and is of significant knowledge to the economist who is interested in the strange and irregular pattern in the Nigerian exchange sector and as such provides the most necessary knowledge of various interactions in the macro-economics of Nigeria [5].

\section{Model Specification, Estimation and Test}

ARIMA is the method introduced by Box and Jenkins. Centered on Autoregressive integrated moving average models, this form of forecasting implements knowledge of autocorrelation analysis [6-7]. The 
technique consists of four distinct phases: Detection, Estimation, Testing and Forecasting of Diagnostics.

\section{Stationarity}

If there is no systematic shift in the mean (no trend), variances and purely seasonal variations have been eliminated, a time series is stationary. In other words, the adjustment would have no effect on the joint distribution, which would depend on the interval, if the value of time origin, $n$, is increased. Mathematically, a time series is said to be stationary if the joint probability distribution of $"\left(t_{1}\right), \ldots \ldots, x\left(t_{n}\right) "$ is the same as the joint distribution of $x\left(t_{1}+n\right), \ldots . . x\left(t_{\mathrm{n}}+n\right)$ for all $t_{1} \ldots \ldots \ldots . . t_{\mathrm{n}}$.

Alternatively, a time series is said to be stationary if: $\left(\mathrm{Y}_{\mathrm{t}}\right)=$ constant for all $\mathrm{t}$

$\operatorname{Var}\left(\mathrm{Y}_{\mathrm{t}}\right)=$ constant for all $\mathrm{t}$

$\operatorname{Cov}\left(Y_{t}, T_{t}+k\right)=$ constant for all $t$

\section{Achieving Stationarity}

Stationarity must be reached before any model is built on the basis of the non-stationary existence of most business and economic time series. In order to achieve stationarity, we can distinguish the data. There will be one point less than the original in the differentiated results [11]. Taking the logarithm or square root will stabilise the variance for non-constant variance. For non-seasonal data, first order differencing is usually sufficient to attain apparent Stationarity so that the new series $\left(y_{1}, \ldots \ldots, n=1\right)$ is formed from the original series $\left(x_{1}\right), \ldots . .\left(x_{\mathrm{n}}\right)$ by $y_{\mathrm{t}}=x_{\mathrm{t}+1}-x_{\mathrm{t}}=\nabla x_{\mathrm{t}+1}$.

Occasionally, second order differencing is required using the operator $\nabla_{2}$ where

$\nabla^{2} \mathrm{x}_{\mathrm{t}+1}=\nabla \mathrm{x}_{\mathrm{t}+2}-\nabla \mathrm{x}_{\mathrm{t}+1}-2 \mathrm{x}_{\mathrm{t}+1}+\mathrm{x}_{\mathrm{t}}$

Hence the number of times that the original series is differenced to achieve Stationarity is the order of homogeneity.

\section{Differencing}

This is a special form of filtering that is particularly helpful in pushing a trend. This is done by subtracting each knowledge from its predecessor in a sequence. First-order difference is necessary for nonseasonal data to achieve apparent stationarity. The definition of the operator of the backshift helps to grasp and articulate various models of ARIMA [8-10].

For example,

$B Y_{\mathrm{t}}=\mathrm{Y}_{\mathrm{t}+1}$ or $B \mathrm{e}_{\mathrm{t}}=\mathrm{e}_{\mathrm{t}+1}$ and $\mathrm{B}^{2} \mathrm{e}_{\mathrm{t}}=\mathrm{e}_{\mathrm{t}-2}$

ARIMA $(1,0,0)$ can be expressed in terms of backshift operator as

$\mathrm{Y}_{\mathrm{t}}=\emptyset_{1} \mathrm{Y}_{\mathrm{t}-1}+\mathrm{e}_{\mathrm{t}}+\mathrm{u}$

Also,

$\mathrm{Y}_{\mathrm{t}}-\emptyset_{1} \mathrm{Y}_{\mathrm{t}-1}=\mathrm{e}_{\mathrm{t}}$

But, $\mathrm{BY}_{\mathrm{t}}=\mathrm{Y}_{\mathrm{t}-1}$

When substituted into equation (3) we obtain

$Y_{t}-\emptyset_{1} B Y_{t}=e_{t}$

Similarly, ARIMA $(2,0,0)$ can be written as

$\left(1-\varnothing B-\varnothing B^{2}\right) Y_{t}=e_{t}$

$$
Y_{t}-Y_{t-1}=\emptyset_{1}\left(Y_{t-1}-Y_{t-2}\right)+\emptyset_{2}\left(Y_{t-2}-Y_{t-3}\right)+e_{t}=(1-B)\left(1-\emptyset_{1} B-\emptyset_{2} B^{2}\right) Y_{t}=e_{t}
$$

\section{ARIMA (p, d, q) Models}

If an observed time series is non-stationary in the mean, then we can difference the series. If Yt is replaced by $\nabla^{\mathrm{d}} X$ in the equation $\emptyset(B) Y_{t}=\theta(B) e_{t}$, then we have a model capable of describing certain types of non-stationary series. Such a model is called an integrated model. The general ARIMA $(p, d, q)$ is of the form:

$\mathrm{W}_{\mathrm{t}}=\sum_{\mathrm{i}=1}^{\mathrm{p}} \emptyset_{\mathrm{i}}+\mathrm{W}_{\mathrm{t}-1}+\sum_{\mathrm{j}=1}^{\mathrm{q}} \emptyset_{\mathrm{j}} \mathrm{e}_{\mathrm{t}-\mathrm{j}}+\mathrm{u}+\mathrm{e}_{\mathrm{t}}$

And $p$ is the order of the AR part, $d$ is the degree of differencing and $q$ is the order of the MA part. An example of ARIMA (p,d,q) is ARIMA $(1,1,1)$ which has one Autoregressive parameter, one level of differencing and one Moving average parameter is given by:

$\mathrm{W}_{\mathrm{t}}=\emptyset_{1} \mathrm{~W}_{\mathrm{t}-1}+\emptyset_{1} \mathrm{e}_{\mathrm{t}-1}+\mathrm{u}+\mathrm{e}_{\mathrm{t}}$

$(1-B) Y_{t}=\emptyset_{1}(1-B) Y_{t-1}+\emptyset_{1} e_{t-1}+u+e_{t}$

\section{Box and Jenkins Method}

Centered on autoregressive integrated moving average models, this forecasting approach incorporates knowledge of autocorrelation analysis. The procedure consists of four main phases, namely: Forecasting Recognition Estimation Diagnostics Check.

\section{Identification}

Determining if the sequence is stationary is the first step in creating an ARIMA model. Stationarity could be accomplished primarily by differentiating the sequence or going for the dickey fuller test if the model is found to be non-stationary. Some transformation modes, such as the log transformation, could also achieve stationarity. Once stationarity has been achieved, the next step is to use the Auto Correlation Function (ACF) and Partial Auto Correlation Function to evaluate the autoregressive (AR) and moving average (MA) order words (PACF). The table below illustrates how ARIMA models' $\mathrm{p}$ and $\mathrm{q}$ orders are defined. 
Table-1: Identification of $p$ and $q$ orders in ARIMA Models

\begin{tabular}{|l|l|l|}
\hline Process & ACF & PACF \\
\hline $\mathrm{AR}_{(\mathrm{P})}$ & Tails off & Cut off after the order q of the process \\
\hline $\mathrm{MA}_{(\mathrm{q})}$ & Cut off after the order q of the process & Tails off \\
\hline $\mathrm{ARMA}_{(\mathrm{p}, \mathrm{q})}$ & Tails off & Tails off \\
\hline
\end{tabular}

\section{Estimation}

The estimation stage starts once the preliminary model is selected. The aim of the calculation is to find estimates of parameters that minimize the mean error in the square. Two techniques are used and these include the least nonlinear squares and measures of maximum probability. The R statistical package was used in this process in the estimation.

\section{Diagnostics Checking}

To ensure that the model is sufficient, the model residuals are examined (random). Diagnostics are as follows: Time plot of the residuals Plot of the residual ACF Normal Quantile Quantile (QQ) Plot of the residuals

\section{Forecasting}

If a suitable ARIMA model has been found to be sufficient, then for a time or several periods ahead, we continue to forecast or predict. The chances of forecast errors, however, are inevitable as the time progresses.

\section{RESULT AND DISCUSSION}

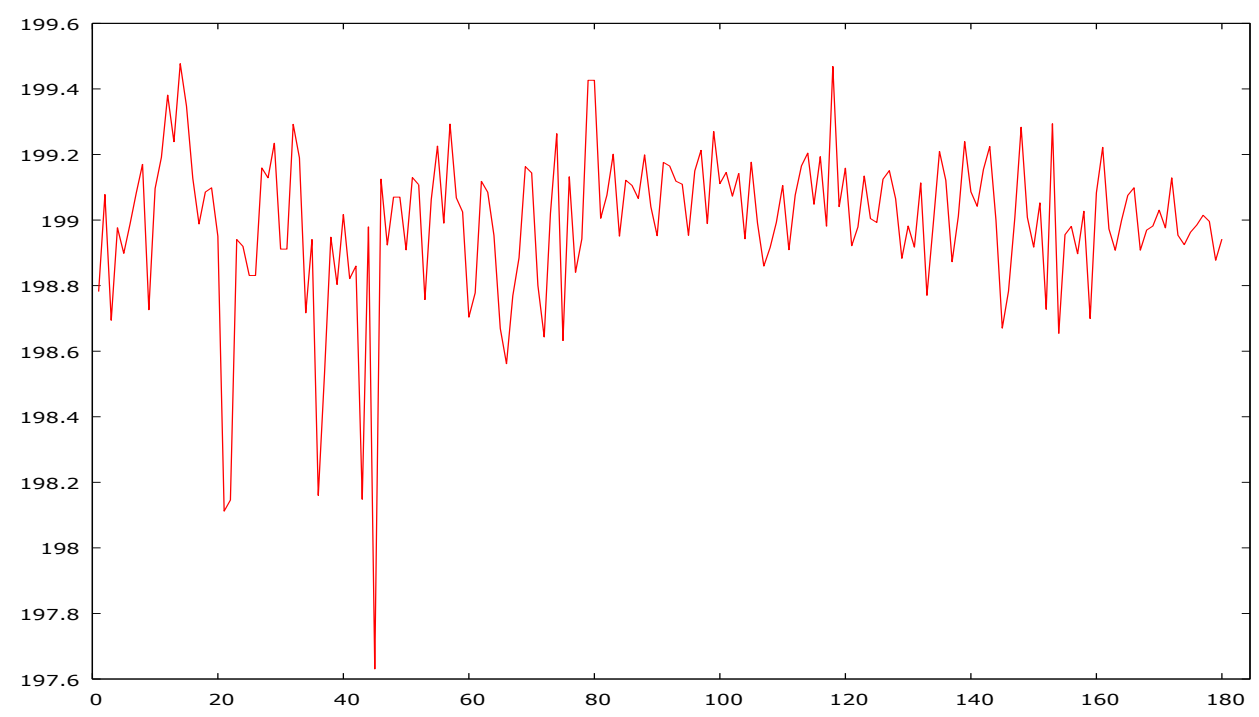

Fig-1: Time Series plot for USdollar_to_Naira_exchangeRate data series

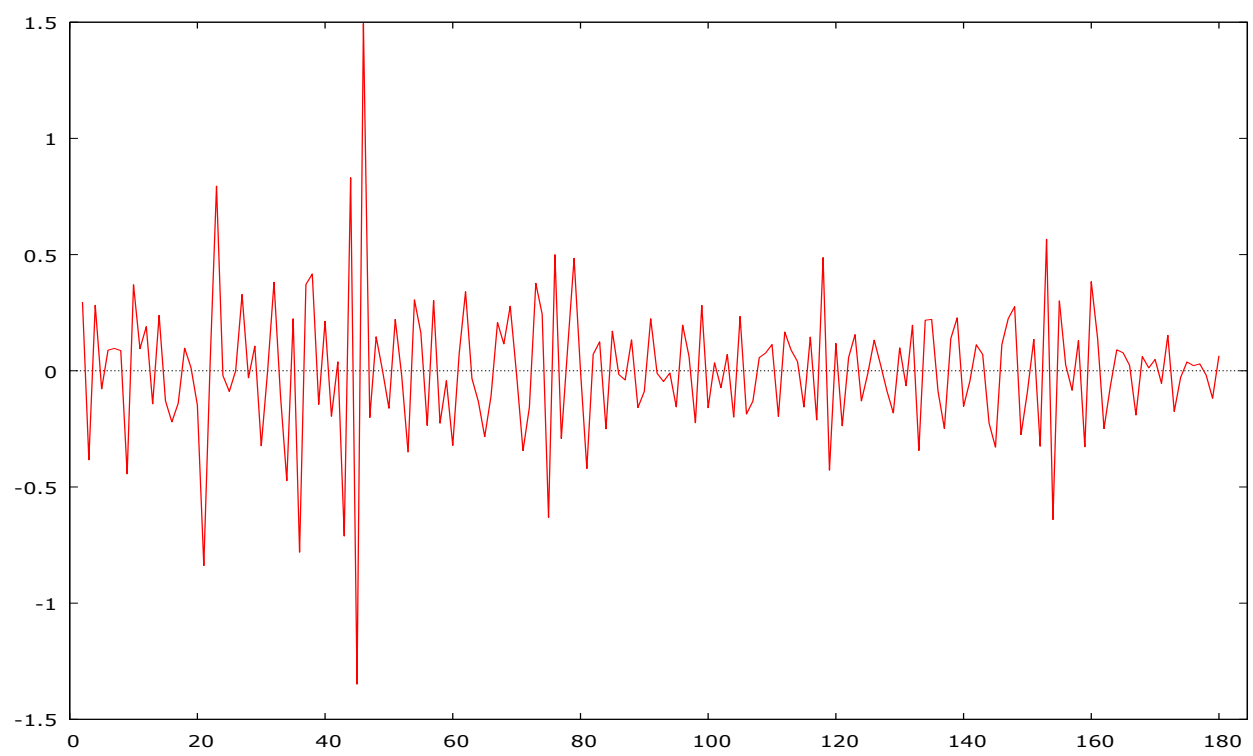

Fig-2: Time Series plot for d_USdollar_to_Naira_exchangeRate data series 
Guobadia Emwinloghosa Kenneth \& Ibeakuzi Precious Onyedikachi., Sch J Phys Math Stat, Jan, 2021; 8(1): 8-13

Table-2: Augmented Dickey-Fuller test for Stationarity of USdollar_to_Naira_exchangeRate data series

\begin{tabular}{|l|l|l|l|}
\hline$d$ & t-statistic & p-value & $\alpha$-value \\
\hline 0 & -0.03167 & 0.6723 & 0.05 \\
\hline 1 & -7.548 & $2.29 \mathrm{e}-012$ & 0.05 \\
\hline
\end{tabular}

Table 3: Identification of Best ARIMA model for USdollar_to_Naira_exchangeRate

\begin{tabular}{|l|l|l|l|}
\hline Model & AIC & BIC & HQC \\
\hline 100 & -12.7096 & -1.1308 & -8.8258 \\
\hline 111 & -6.4836 & 6.2659 & -1.3138 \\
\hline 010 & 70.7679 & 73.95527 & 72.0603 \\
\hline 011 & -3.5461 & 6.0161 & 0.3313 \\
\hline $\mathbf{1 0 1}$ & $\mathbf{- 1 5 . 2 2 6 2}$ & $\mathbf{- 2 . 4 5 4 3}$ & $\mathbf{- 1 0 . 0 4 7 7}$ \\
\hline
\end{tabular}

Residual ACF

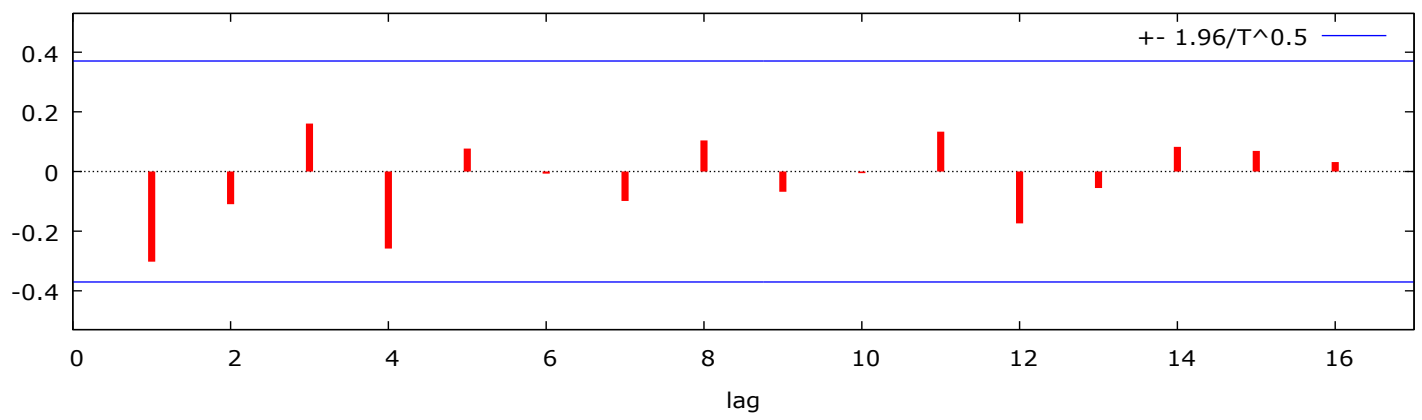

Residual PACF

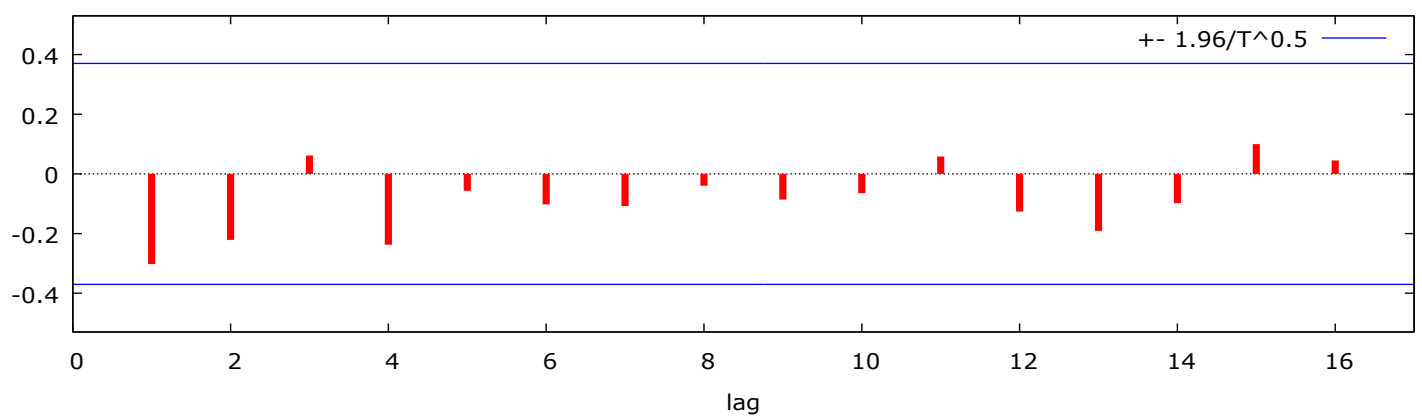

Fig-3: Diagnostic check on the best model for USdollar_to_Naira_exchangeRate

Table-4: Residual autocorrelation function $* * *, * *, *$ indicate significance at the $1 \%, 5 \%, 10 \%$ levels Using standard error $1 / \mathrm{T}^{\wedge} 0.5$

\begin{tabular}{|c|c|c|c|}
\hline \\
\hline LAG & $\mathrm{ACF}$ & PACF & Q-stat. [p-value] \\
\hline 1 & -0.0197 & -0.0197 & - \\
\hline 2 & 0.0737 & 0.0734 & - \\
\hline 3 & -0.0872 & -0.0849 & $2.4791[0.115]$ \\
\hline 4 & 0.0209 & 0.0130 & $2.5603[0.278]$ \\
\hline 5 & 0.0540 & 0.0678 & $3.1070[0.375]$ \\
\hline 6 & 0.0208 & 0.0126 & $3.1885[0.527]$ \\
\hline 7 & -0.0847 & -0.0920 & $4.5461[0.474]$ \\
\hline 8 & 0.0068 & 0.0129 & $4.5549[0.602]$ \\
\hline 9 & 0.0769 & 0.0943 & $5.6872[0.577]$ \\
\hline 10 & $-0.1480 * *$ & $-0.1737 * *$ & $9.9089[0.271]$ \\
\hline 11 & -0.0444 & -0.0621 & $10.2906[0.327]$ \\
\hline 12 & -0.0238 & 0.0340 & $10.4013[0.406]$ \\
\hline 13 & 0.0064 & -0.0153 & $10.4093[0.494]$ \\
\hline 14 & -0.0021 & -0.0355 & $10.4101[0.580]$ \\
\hline 15 & 0.0853 & 0.1180 & $11.8554[0.540]$ \\
\hline 16 & -0.0069 & 0.0299 & $11.8648[0.617]$ \\
\hline
\end{tabular}


Guobadia Emwinloghosa Kenneth \& Ibeakuzi Precious Onyedikachi., Sch J Phys Math Stat, Jan, 2021; 8(1): 8-13

Table-5: Forecasting for USdollar_to_Naira_exchangeRate using ARIMA $(1,0,1)$

For $95 \%$ confidence intervals, $z(0.025)=1.96$

\begin{tabular}{|c|c|c|c|}
\hline Obs & Prediction & std. error & $95 \%$ interval \\
\hline $\begin{array}{l}\mathbf{2 0 2 0} \\
1\end{array}$ & 398.670 & 0.226787 & $(398.526,399.415)$ \\
\hline 2 & 398.677 & 0.231501 & $(398.523,399.431)$ \\
\hline 3 & 398.681 & 0.233778 & $(398.523,399.440)$ \\
\hline 4 & 398.684 & 0.234887 & $(398.524,399.445)$ \\
\hline 5 & 398.687 & 0.235430 & $(398.525,399.448)$ \\
\hline 6 & 398.688 & 0.235695 & $(398.526,399.450)$ \\
\hline 7 & 398.689 & 0.235825 & $(398.527,399.452)$ \\
\hline 8 & 398.690 & 0.235889 & $(398.528,399.455)$ \\
\hline 9 & 398.691 & 0.235900 & $(398.528,399.453)$ \\
\hline 10 & 398.692 & 0.235906 & $(398.529,399.458)$ \\
\hline 11 & 398.693 & 0.235914 & $(398.530,399.462)$ \\
\hline 12 & 398.694 & 0.235917 & $(398.531,399.464)$ \\
\hline $\begin{array}{l}2021 \\
1\end{array}$ & 398.760 & 0.244717 & $(398.616,399.515)$ \\
\hline 2 & 398.767 & 0.244511 & $(398.613,399.531)$ \\
\hline 3 & 398.861 & 0.244718 & $(398.613,399.550)$ \\
\hline 4 & 398.864 & 0.244817 & $(398.614,399.555)$ \\
\hline 5 & 398.867 & 0.244410 & $(398.615,399.558)$ \\
\hline 6 & 398.868 & 0.244615 & $(398.616,399.560)$ \\
\hline 7 & 398.869 & 0.244815 & $(398.617,399.562)$ \\
\hline 8 & 398.960 & 0.244819 & $(398.618,399.565)$ \\
\hline 9 & 398.961 & 0.244900 & $(398.618,399.563)$ \\
\hline 10 & 398.962 & 0.244906 & $(398.619,399.568)$ \\
\hline 11 & 398.963 & 0.244918 & $(398.620,399.572)$ \\
\hline 12 & 398.964 & 0.244919 & $(398.621,399.574)$ \\
\hline
\end{tabular}

The time series plot of the USdollar_to_Naira_exchangeRate data series on Fig-1 shows a strong evidence of a non-stationary series, the non-stationarity was also confirmed with the help of the augmented dickey-fuller (ADF) test on Table-2, by using first order differencing transformation, we obtained a t-statistic lesser than what was obtained at $\mathrm{d}$ $=0$, and a p-value lesser than $5 \%$ alpha level. Thus, we select the condition that $\mathrm{d}=1$ and transform the data using first order differencing to make it stationary as seen on fig 2. Five tentative models were entertained, and the model with the minimum AIC, BIC and HQC, ARIMA $(1,0,1)$ defined by $Y_{t}=398.992+$ $0.7004 Y_{t-1}-0.4955 Y_{t-1}+e_{t}$ was chosen as the best model. To verify that the chosen ARIMA $(1,0,1)$ is an appropriate model for USdollar_to_Naira_exchangeRate, a diagnostic check is done using residual ACF/PACF plot at different lags and testing the significance of the correlations up to 16 lags by Q statistic and respective p-values. Fig-3 above clearly shows evidence of random walk as the values are within the bounds and undulate about zero. Hence we uphold the first order differencing. Clearly, none of the correlations is significantly different from zero at a reasonable level. The ACF and PACF of the residuals also indicate good fit of the model and the respective pvalues on Table- 4 are greater than the $\alpha$-value which is a desirable result. This proves that the selected ARIMA $(1,0,1)$ is appropriate for modeling
USdollar_to_Naira_exchange Rate. Finally, the forecast on table 5, shows slight daily increase in the exchange rate for subsequent periods.

\section{CONCLUSION}

The main objective of this study was to develop an ARIMA model that could help predict NAIRA/USD exchange rate, five tentative models were developed out of which $\operatorname{ARIMA}(1,0,1)$ was chosen as the best based on the lowest values of information criterion. The model was further subjected to series of diagnostic testing and was ultimately used for forecasting. The forecasted values suggest an increase in the exchange rate between the two currencies.

\section{REFERENCES}

1. Nwokike Chukwudike C, Ugoala, Chukwuma B, Obubu Maxwell, Uche-Ikonne Okezie O, Offorha Bright C, and Ukomah Henry I. (2020). Forecasting Monthly Prices of Gold Using Artificial Neural Network. Journal of Statistical and Econometric Methods. 9(3), 19-28.

2. Nwokike, C. C., Offorha, B. C., Obubu Maxwell, Uche-Ikonne, O. O. and Onwuegbulam, C. C. (2020). ARIMA Modelling of Neonatal Mortality in Abia State of Nigeria. Asian Journal of Probability and Statistics. 6(2), 54-62. 
Guobadia Emwinloghosa Kenneth \& Ibeakuzi Precious Onyedikachi., Sch J Phys Math Stat, Jan, 2021; 8(1): 8-13

3. Yang W. (2018). The Prediction of Gold Price Using ARIMA Model. Advances in Social Science, Education and Humanities Research. 196 (2). 273276.

4. Guha B. and Bandyopadhyay G. (2016). Gold Price Forecasting Using ARIMA Model. Journal of Advanced Management Science. 4(2), 117-121.

5. Gudan, Jovita. (2016). Modeling and Forecasting Exchange Rates. Lithuanian Journal of Statistics. 55. 19-30.

6. Osuji, G.A., Okoro, C.N., Obubu, M., ObioraIlouno H.O. (2016). Effect of Akaike Information Criterion on Model Selection in Analyzing AutoCrash Variables. International Journal of Sciences: Basic and Applied Research. 26(1):98-109.

7. Panel carlos, Eduardo castillo-Maldonado, Fidel pérez-Macal (2013). Assessment of Models to
Forecast Exchange Rates: The Quetzal-U.S. Dollar. Journal of Applied Economics. 16(1), 7199.

8. Bailliu, J., King, M. R. (2005), What Drives Movements in Exchange Rates? Bank of CanadaRevew, Autumn. 3-16.

9. Box G E, Jenkinks G M; "Time series analysis: Forecasting and control"; Holden Day, San Francisco.

10. Erlat, Guzin and Arslaner, Ferhat (997). Measuring Annual Real Exchange Rates Series for Turkey. Yapi Kredi Economic Review. 2(8): 35-61.

11. Obubu Maxwell, Babalola A. Mayowa, Ikediuwa U. Chinedu, Amadi Peace (2018). Modeling Count Data; a Generalized Linear Model Framework. American Journal of Mathematics and Statistics. 8(6): 179-183 doi:10.5923/j.ajms.20180806.03. 